\title{
New fee structure proposed by FDA might lead to more talk
}

Ever since 1992, when US lawmakers passed the Prescription Drug User Fee Act (PDUFA) to accelerate review of new drugs by the US Food and Drug Administration, industry money has had an increasingly important role in fueling the regulatory agency. In the program's first year, drug companies paid less than $\$ 9$ million total to the FDA through the initiative. But in the past two decades the amount has ballooned; this year, the agency anticipates receiving at least $\$ 619$ million in user fees, composing roughly $65 \%$ of its budget for overseeing human drugs.

Despite the torrent of funds, the FDA has still failed to meet its goal of completing the review of $90 \%$ of new drug applications within ten months. Industry isn't exactly pleased with this report card, and they have spent the past year in negotiations with the agency to plan how the fees can be used to make drug review more efficient.

On 1 September, the FDA released a draft of its performance goals and procedures for the fifth iteration of PDUFA, which is slated for reapproval in 2012. The proposed plan takes a 'more is more' approach: user fees will increase 6\% between 2013 and 2017, and, in exchange, industry is promised better communication throughout the entire drug review process.

"It's just a much more standardized set of communication and timelines," says Michael Hay, a senior biotechnology analyst at Sagient Research Systems, a San Diego-based market research firm focusing on the investment and healthcare industries. "The end result is that, hopefully, a higher rate of [new drug] applications will be approved on the first review."

\section{Communication breakdown}

When the FDA says "communication," it really means "meetings." The proposal calls for a new 60-day pre-filing period for new drug and biologic applications during which drug companies can meet with the FDA to map out the review process. "Drug sponsors can make the FDA aware of the goals and strategy for the development of the drug, and the agency can give any comments and express any concerns with the study protocol," says James Czaban, chief FDA lawyer at Wiley Rein in Washington, DC. Sponsors preparing drug approval applications then have time to address those issues, which they otherwise may not have learned of until later in the process.

The new PDUFA proposal calls for two new mandatory meetings during the drug review process: a mid-cycle review, to discuss the need for a risk evaluation and mitigation strategy, and a late-cycle review, to lay out issues the advisory committee might raise. The user fees will even fund a new tenemployee office within the FDA to organize the meetings themselves and to smooth out correspondence between sponsors and the agency. Notably, the FDA plans to hold at least four public meetings each year to receive input from patients, doctors and researchers on side effects of drugs both pending approval and already on the market. "It will be very interesting to see how this works in practice, as it seems actually like a lot of work," says Hay.

However, the measure of success is still how many applications the FDA reviews within ten months, and extra hand-holding doesn't ensure that efficiency. "More meetings are better, but meetings don't replace action," says Peter Pitts, president and cofounder of the Center for Medicine in the Public Interest, a New York-based think tank, and former associate commissioner for external relations at the FDA. Without user fees, the drug agency will shut down, so drug sponsors can't really threaten to withhold those fees if there is no improvement. "If the FDA slides on its review times, there have to be consequences to those actions," says Pitts. "Industry has been kind of wussy in terms of holding the FDA's feet to the fire."

Hannah Waters is databases and statistical power," says Jacques Ravel, a microbiologist at the University of Maryland School of Medicine in Baltimore. Ravel helped sequence the 2001 anthrax strain while at The Institute for Genomic Research in Rockville, Maryland. If the next biological strike involves, say, bubonic plague, sequencing the attack strain will be no good unless investigators have a vast array of plague bacteria for comparison.

\section{Virtual reality}

The FBI is starting with a "virtual collection," says Jason Bannan, senior biological programs advisor for the Bureau's laboratory in Quantico, Virginia. That is, an FBI working group is figuring out what strains are available in collections across the country, so it can quickly access them when needed. Once this work is complete, the Bureau will proceed to calling in samples for a physical strain library.

Over the past decade, government leaders have also focused on how to better integrate the biodefense efforts of disparate agency cultures at, for example, the FBI and the US Centers for Disease Control and Prevention. In 2009, the White House issued a microbial forensics strategy, noting that current capabilities only "scratch the surface" of what's needed. Key recommendations included better technology and interagency coordination. To address these issues, last year the government established the Interagency Microbial Forensics Advisory Board to coordinate research and development among different departments.
The various agencies "are generally singing off the same page now," says Thomas Inglesby, director of the Center for Biosecurity at the University of Pittsburgh Medical Center in Pennsylvania.

But some experts worry that the collaboration has not yet trickled down to local health authorities, too. At an Institute of Medicine workshop on pathogen surveillance held in mid-September in Washington, DC, Joe Gibson, director of epidemiology for the Marion County Public Health Department in Indianapolis, Indiana, noted that patient privacy laws and a general reluctance of schools and health departments to share epidemiological data hinder his department's access to surveillance data and suggested that building trust and clarifying how data will be used would help foster cooperation.

Even as scientists hammer out the details of bioterrorism countermeasures, they are already using advances in the microbial forensics field to deduce the origins of naturally occurring threats to public health. Biologists have used these techniques to ferret out the sources of severe acute respiratory syndrome (SARS), recent E. coli infections in Germany and the cholera outbreak in Haiti following the 2010 earthquake.

"On the whole, there's a better appreciation of what microbial forensics can and can't deliver," Inglesby says. The science can only provide a clue, not a conclusion. Good old-fashioned detective work, he adds, is still necessary to catch the bad guy.

Amber Dance 